\title{
To mesh or not to mesh? That is the question
}

\author{
Steven Swift
}

Received: 14 February 2011 / Accepted: 10 March 2011 /Published online: 2 April 2011

(C) The International Urogynecological Association 2011

This question is probably the most commonly discussed topic when experts in pelvic floor medicine and reconstructive surgery (FPMRS or urogynecologists) get together or meet our colleagues in general gynecology. Until recently, the answer to this question was pure speculation because there were no prospective randomized trials to give us guidance. Now, however, we are seeing the preliminary results of well-done randomized trials, and we are getting a clearer picture of what role mesh plays in pelvic reconstruction surgery.

To fully understand where we are today, we need to remember where we came from. In 1997, Olsen et al. published a landmark article in Obstetrics and Gynecology reporting that up to $30 \%$ of subjects who underwent prolapse surgery in the Kaiser Healthcare system of the Pacific Northwest had repeat prolapse surgery at some point. [1] This data did not specify if recurrence was in the same compartment as the previous surgery, only that $30 \%$ of study charts reviewed (charts of patients who were undergoing pelvic organ prolapse surgery) reported at least one prior prolapse procedure. Shortly after this publication, in 2001, Weber et al. published the results of a study comparing three different anterior repair procedures at 23 months' follow-up. [2] They reported up to a $70 \%$ failure rate after a standard anterior repair. This data taken with the prior report by Olsen strongly suggested that we were in need of something to help us provide long-term durable surgical repairs of pelvic organ prolapse. In this same time frame (2001), there was a National Institutes of

\section{S. Swift $(\bowtie)$}

Department of Obstetrics and Gynecology,

Medical University of South Carolina,

Charleston, SC, USA

e-mail: swifts@musc.edu
Health (NIH) consensus conference on defining the disease state of pelvic organ prolapse. [3] The outcome of the consensus conference was that POPQ stage 0 was normal, POPQ stage I was "okay", and POPQ stages II, III, and IV were prolapse. The authors of the consensus conference paper recognized that they did not have much evidence to base their decisions on, but felt it important to propose a definition so that we could begin collecting meaningful data. So it was in this environment that the field of urogynecology and female urology found itself: a definition of a disease state based on nothing but expert opinion and surgical procedures that appeared almost futile in their inability to correct disease.

Enter the use of mesh to re-enforce pelvic floor reconstructive surgery. Early reports on incorporating mesh into reconstructive surgery were small series that used a variety of overlays, from absorbable synthetic meshes to biologic grafts to non-absorbable synthetic meshes., [4, 5] These reports described combining standard native tissue repairs with absorbable mesh, non-absorbable mesh or biologic grafts sutured in place as an overlay. The results from several small series were encouraging but still not acceptable.

Now enter the prolapse mesh kits. These started to become popular in and around 2005-2006 as they began to show up as case series at our annual scientific meetings. These kits, for the most part, used synthetic non-absorbable mesh and had anchoring arms that passed through the obturator space and/or the sacrospinous ligament. Their advantage was that they provided a permanent synthetic supportive layer with solid fixation points. This appeared to be the answer for the problems we were having with our faulty surgical repairs.

Fast forward a few years to where we are in 2011. We are now seeing the results of good prospective randomized 
trials comparing synthetic mesh kits with native tissue repairs, and the results are helpful with clinical decision making [6], [7].

What have we learned? First, that synthetic mesh kits provide greater anatomic support for the vaginal walls than standard native tissue repairs. Second, that overall, patients are highly satisfied with the outcomes of prolapse surgery whether done with synthetic mesh kits or standard native tissue. Third, the re-operation rate from standard native tissue repairs is probably closer to $10 \%$ then $30 \%$. Finally, that inserting a synthetic mesh has a downside and overall reoperation rates with synthetic meshes are still roughly $10 \%$ (some for recurrence and some for mesh excision from complications related to mesh placement). So inserting nonabsorbable synthetic meshes reduces anatomic recurrence but adds little to symptomatic recurrence and patient satisfaction with their outcome.

Why is this? Synthetic non-absorbable mesh kit surgery has demonstrated superior results at elevating the various vaginal walls over native tissue repairs. This finding is consistent across all studies. However, when patients are asked via validated symptom questionnaires how their symptoms responded to surgery, there is no difference in improvement between synthetic non-absorbable mesh kit repairs and native tissue repairs. [8] Generally, over $90 \%$ of patients in either group are pleased with their results. This is a bit of a disconnect and reveals one of the problems with our current definition of pelvic organ prolapse. The NIH definition is too inclusive. By using POPQ stage II or greater, $30 \%$ of normal asymptomatic women fall into the disease category of having pelvic organ prolapse despite absence of symptoms. A better definition (and one that is gaining acceptance in many studies) is any vaginal POPQ points being at the hymenal remnants or beyond (this includes some stage II and all stages III and IV). These women classically have symptoms attributable to prolapse and if you can get the vaginal walls above the hymenal remnants with surgery patients, for the most part, report that they are symptom free. So our old definitions of pelvic organ prolapse are not sound and led to the earlier findings of very high failure rates. We set the bar for anatomic cure too high.

We can now say that approximately $5-10 \%$ of subjects undergoing pelvic organ prolapse reconstruction surgery will require re-operation. For those having undergone native tissue repairs, the re-operation will be related to recurrent prolapse. For those having undergone repair with a synthetic non-absorbable mesh kit, it will be for either recurrent prolapse or a complication of the mesh.

So, how do we answer the question; to mesh or not to mesh? I strongly believe that both approaches are adequate and serve our patients well. We need to have frank discussions with our patients. If we chose to perform a native tissue repair, then we need to tell our patients we have good success rates, but there is about a $5-10 \%$ chance that we will need to re-operate for a return of their prolapse. If we chose to use a synthetic non-absorbable mesh kit, we need to counsel our patients that about $5-10 \%$ of the time we will need to re-operate for either a mesh complication or a recurrence of the prolapse. Neither approach is currently superior as they both have pros and cons. Our next job as a specialty is to define which patients are at greatest risk of failing native tissue repairs and steer them towards a mesh kit repair. Conversely, we need to better define the risk factors for a mesh complication. Only then can we truly provide the best care to our patients.

\section{References}

1. Olsen AL, Smith VJ, Bergstrom JO, Colling JC, Clark AL (1997) Epidemiology of surgically managed pelvic organ prolapse and urinary incontinence. Obstet Gynecol 89:501-506

2. Weber AM, Walters MD, Piedmonte MR, Ballard LA (2001) Anterior colporraphy: a randomized trial of three surgical techniques. Am J Obstet Gynecol 185:1299-1306

3. Weber AM, Abrams P, Brubaker L, Cundiff G, Davis G, Domchowski RR et al (2001) The standardization of terminology for researchers in female pelvic floor disorders. Int Urogynecol J 12:178-186

4. Sand PK, Koduri S, Lobel RW, Winkler HA, Tomezsko J, Culligan PJ et al (2001) Prospective randomized trial of polyglactin 910 mesh to prevent recurrence of cystoceles and rectoceles. Am J Obstet Gynecol 184:1357-1364

5. Kwon C, Goldberg R, Evaston IL, Koduri S, Franklin WI, Gandhi $S$ et al (2002) Preliminary results of a prospective randomized trial of tutoplast processed fascia lata to prevent recurrent cystoceles and rectoceles. J Urol 167:203

6. Niemenen K, Hiltunen R, Takala T, Heiskanen E, Merikari M, Neimi K et al (2010) Outcomes after anterior vaginal wall repair with mesh: a randomized, controlled trial with 3 year follow-up. Am J Obstet Gynecol 203:235

7. Sokol A, Iglesia C, Sokol R, Kudish B, Gutman R, Shveiky D et al (2010) 1-year results of a randomized clinical trial of vaginal mesh for prolapse (VAMP). Fem Pel Med Reconst Surg 16:S62, abstract

8. Maher et al. Surgical management of pelvic organ prolapse in women. Cochrane Database of Systematic Reviews 2010, Issue 4. Art. No.: CD004014. doi:10.1002/14651858.CD004014.pub4 